\title{
Experimental validation of pressure drop models during flow boiling of R134a - effect of flow acceleration and entrainment
}

\author{
Tomasz Muszynski ${ }^{1, *}$, Rafal Andrzejczyk ${ }^{1}$, and Carlos Dorao $^{2}$ \\ ${ }^{1}$ Gdansk University of Technology, Gdansk, Poland \\ ${ }^{2}$ NTNU, Trondheim, Norway
}

\begin{abstract}
A crucial step to assure proficient work of power and process apparatus is their proper design. A wide array of those devices operates within boiling or condensation of the working fluid to benefit from high heat transfer rates. Two-phase flows are associated with high heat transfer coefficients because of the latent heat of evaporation and high turbulence level between the liquid and the solid surface. Predicting heat transfer coefficient and pressure drop is a challenging task, and has been pursued by researchers for decades. In the case of diabatic flows, the total pressure drop is due to the change in kinetic and potential energy. The article presents detailed boiling pressure drops data for R134a at a saturation temperature of $19.4^{\circ} \mathrm{C}$. Study cases have been set for a mass flux varying from 300 to $500 \mathrm{~kg} / \mathrm{m}^{2} \mathrm{~s}$. Presented data along with the data reduction procedure was used to obtain the momentum pressure drop values during flow boiling. The study focuses on experimental values of momentum pressure drop component and its prediction based on various void fraction models and entrainment effects.
\end{abstract}

\section{Introduction}

Rising energy costs and environmental considerations are driving industry for renewable energy use [1], major gains can be made by increasing the efficiency of energy utilization, i.e. recovering low-grade waste heat [2], improving process efficiency [3], or utilizing thermal energy [4].

An essential step to assure efficient work of power and process apparatus is their proper design [5,6]. A wide range of those devices operates within boiling or condensation of the working fluid to take advantage of high heat transfer coefficients [7]. Two-phase flows are associated with large rates of heat transfer because of the latent heat of evaporation and enhancement of the turbulence level between the liquid and the solid surface $[8,9]$. High heat fluxes can also be obtained by means of numerous enhancement technologies [10-12]. Predicting heat transfer coefficient and pressure drop is a challenging task, and has been pursued by various research for decades. In the case of diabatic flows, it has been shown that total pressure drop is the summation of acceleration, static and frictional pressure drop [13].

The frictional pressure drop of two-phase flow is a function of fluid properties and significantly depends on mass and volume fractions of the mixture. Past research aimed at predicting the frictional pressure drop, includes a large number of studies that rely on either the Homogeneous Equilibrium Model (HEM) or semiempirical correlations [14].

The research by Revellin and Haberschill [15] focused on experimental frictional pressure drop predictions, compared to 485 database points for smooth tubes from the literature. It was reported that the Quibén [16] displayed the best consistency with experimental data points. The $74 \%$ of the data were predicted by the latter model within a 30\% error band. Furthermore, model predicts a maximum pressure drop before the annular-to-dryout transition, i.e. as usually in the annular flow regime. The frictional pressure drop of R-134a investigations in $5 \mathrm{~mm}$ diameter smooth pipes was presented by Andrzejczyk et al. [17]. The study showed that updated Quiben [16] model by Thome [13] and Zhang and Webb [18] obtain the best consistency with experiments with a mean absolute deviation (MAD) under $20 \%$. It was also noted that both models predict well peak pressure drop.

Garcia [19] presented an experimental study on R407C two-phase flow in a smooth copper tube, alternating from 4.5 to $8.0 \mathrm{~mm}$ inner diameter, evaporation pressures (10 and 12 bar), mass flux (from $180 \mathrm{~kg} /\left(\mathrm{m}^{2} \mathrm{~s}\right)$ to $\left.500 \mathrm{~kg} /\left(\mathrm{m}^{2} \mathrm{~s}\right)\right)$. The effects of vapor qualities, diameters, mass fluxes and saturation pressures on the two-phase flow pressure drop were studied. The experimental data were compared with 18 most common correlations. Results showed that Cicchitti et al. [20] and Sun and Mishima [21] correlations provide the best results.

The article presents detailed boiling pressure drops data for R134a at a saturation temperature of $19.4^{\circ} \mathrm{C}$ with inlet subcooling of $7 \mathrm{~K}$ and $14 \mathrm{~K}$. Study cases have been set for a mass flux varying from 300 to $500 \mathrm{~kg} /\left(\mathrm{m}^{2} \mathrm{~s}\right)$. Presented data along with data reduction procedure was

\footnotetext{
* Corresponding author: Tomasz.Muszynski@.pg.edu.pl
} 
used to obtain the momentum pressure drop values during flow boiling.

The study focuses on experimental values of momentum pressure drop component and its prediction based on various void fraction models and entrainment effects. The primary objectives of the present study are to:

-Provide an experimental database including multiple data points in transition and dryout flow regions for two-phase total pressure drop.

- Provide an experimental procedure for obtaining acceleration pressure drop in a horizontal channel, and recognize its effect on values of total pressure drop in a horizontal tube.

- Conduct a systematic assessment of the entrainment on total pressure drop.

\section{Experimental Setup}

In order to obtain experimental values of momentum pressure drop component, the experimental facility is an R134a loop consisting of a reservoir of refrigerant, a pump, a conditioner, a flow meter, a heated test section, a visualization glass, an adiabatic section and a condenser. The loop is schematically represented in figure 1 .

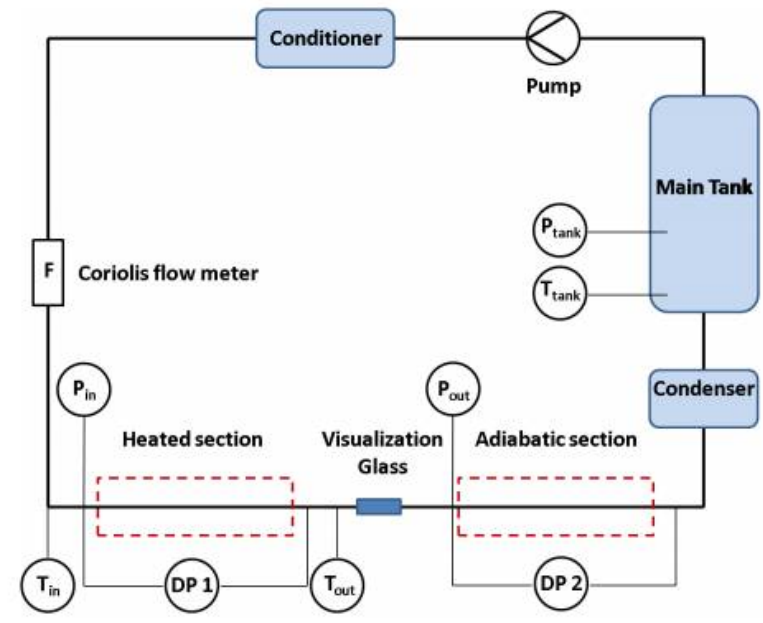

Fig. 1. Schematic of the test facility.

The fluid pressure in the loop is set by controlling the temperature in the main tank where the refrigerant is at saturation conditions. The fluid is circulated by a magnetically coupled gear pump. The conditioner is a shell and tube heat exchanger with glycol in the shell side which is used for adjusting the R134a inlet temperature. The glycol temperature is controlled by the air-cooled chiller. The refrigerant flow rate is measured by a Coriolis type mass flow meter. The heated section is made of stainless steel, as a seamless pipe. The tube is electrically heated by Joule effect with the use of a low voltage DC power supply. The section is thermally insulated with a thick layer of mineral wool, thus thermal losses are neglected. The section is $2 \mathrm{~m}$ long, with $5 \mathrm{~mm}$ and $8 \mathrm{~mm}$ internal and external diameter respectively.
Nine galvanically separated thermocouples are distributed along the tube wall surface, additional two are inside the tube in order to measure the local fluid temperature. The adiabatic test section is a thermally insulated $1 \mathrm{~m}$ long stainless steel pipe with an inner diameter of $5 \mathrm{~mm}$ and $8 \mathrm{~mm}$ outer diameter. The piping system at the supply and outlet of the sections is made with similar pipe dimensions, thus compression and expansions effects are eliminated.

The measurements data are acquired by National Instruments CompactRIO data acquisition system. The signals from measuring devices were processed with the aid of the LabVIEW application. The temperatures, absolute pressures, pressure differences and mass flow rates were acquired at a frequency of $2 \mathrm{~Hz}$. For every experimental point - about 100 data points were acquired. Additionally, in order to verify the steady-state conditions, data points were doubled after 15 minutes. Two-phase total pressure drop was directly measured with a differential pressure transducer, same type differential pressure transducer was used to measure adiabatic pressure drop at the second test section. The heat flux was determined according to eq.:

$$
\dot{q}=\frac{\dot{Q}_{e l}}{A_{w}}
$$

The absolute pressure at the inlet and outlet of the heated section was also recorded and was used for obtaining the saturation temperature $T_{\text {sat }}$ of the fluid based on the equilibrium thermodynamic properties using NIST REFPROP fluid database [22]. The fluid outlet quality $\left(x_{\text {out }}\right)$ was determined from mass and energy conservation equation (2).

$$
x_{\text {out }}=\frac{\dot{q} \pi D_{i} L-m c_{p l} \Delta T_{\text {sub }}}{m h_{l v}}
$$

where: $h_{l v}$ - is the latent heat of evaporation, $L-$ is the length of the heated section, $\dot{m}$ - mass flow rate of the

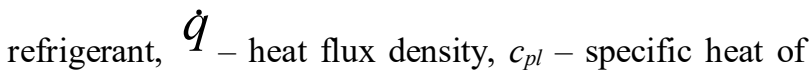
liquid phase, $\Delta T_{\text {sub }}$ - is the inlet liquid subcooling.

The local heat flux as the function of generated Joule heat is assumed to be constant during the evaporation process along the length of the tube. In order to determine the reliability of the experimental results, an uncertainty analysis was conducted on all measured quantities as well as the quantities calculated from the measurement results. Uncertainties were estimated according to the standard procedures described by NIST [23].

\section{Results}

The total pressure drop of fluid $\Delta p_{\text {total }}$ is the summation of acceleration, static and frictional pressure drop according to eq (3) if acceleration and static pressure drop are present. 


$$
\Delta p_{\text {total }}=\Delta p_{\text {mom }}+\Delta p_{\text {frict }}+\Delta p_{\text {grav }}
$$

where $\Delta p_{\text {grav }}$ is the elevation head pressure drop and can be omitted in case of a horizontal tube, $\Delta p_{\text {mom }}$ is the momentum pressure drop created by the acceleration of the flow in a heating/cooling process, and $\Delta p_{\text {frict }}$ is the frictional pressure drop of two-phase flow. Most commonly [24-27] the momentum pressure is expressed by means of eq. (4).

$$
\Delta P_{m o m}=G^{2}\left\{\left[\frac{x^{2}}{\rho_{g} \varepsilon}+\frac{(1-x)^{2}}{\rho_{l}\left(1-\varepsilon^{2}\right.}\right]_{o u t}-\left[\frac{x^{2}}{\rho_{g} \varepsilon}+\frac{(1-x)^{2}}{\rho_{l}(1-\varepsilon)}\right]_{i n}\right\}_{(4)}
$$

Differences between void fraction correlations are minor, therefore in the further analysis, only three formulas were used. The author's previous studies $[17,28,29]$ have shown that the predictions given by various methods differ significantly, therefore a modification of Thome [13] approach was proposed. The modification proposes to calculate the friction pressure drop at the interface of the liquid-vapor mixture based on modified velocity due to entrainment.

The velocity is calculated based on the density of the vapor-droplet mixture at the core of the annular flow. It is calculated based on a homogeneous flow for the core flow as follows

$$
\rho_{c}=\left(1-\varepsilon_{C}\right) \rho_{L}+\varepsilon_{C} \rho_{V}
$$

where $\varepsilon_{c}$ is the void fraction of the core flow:

$$
\varepsilon_{C}=\frac{\varepsilon}{\varepsilon+E(1-\varepsilon)}
$$

The liquid entrainment fraction correlation by Tibiriçá [30] used in this study:

$$
E=\left(1+10^{6.8592}\left(\frac{\rho_{V}}{\rho_{L}}\right)^{0.6267} W e_{j v}^{-1.1641} \operatorname{Re}_{L}^{-0.3988}\right)^{-1}
$$

where the superficial gas velocity Weber number is defined as:

$$
W e_{j v}=\frac{\rho_{v} \cdot j_{v}^{2} \cdot D}{\sigma}
$$

The superficial gas velocity is calculated as:

$$
j_{v}=\frac{x \cdot G}{\rho_{v}}
$$

and liquid Reynolds number :

$$
\operatorname{Re}_{L}=\frac{G \cdot D}{\mu_{L}}
$$

The details on calculation of the friction factor during the annular flow are presented in detail in [13].
The obtained experimental pressure drop data at the were compared with the Darcy-Weisbach correlation, assuming the friction coefficient according to the Haaland [31] and Blasius equation, with pipe internal roughness height given by supplier lower than $0.03 \mathrm{~mm}$.

Adiabatic pressure drops as indicated in the introduction can be measured after preparation of vaporliquid mixture in heated section. Varying the inlet subcooling temperature of working fluid will influence the amount of heat necessary to obtain same vapor quality. Figure 2 shows the experimental two-phase pressure drop of the $5 \mathrm{~mm}$ tube as a function of mass flux and heat flux of R134a at different subcooling temperatures, at a saturation temperature of $19.4^{\circ} \mathrm{C}$.

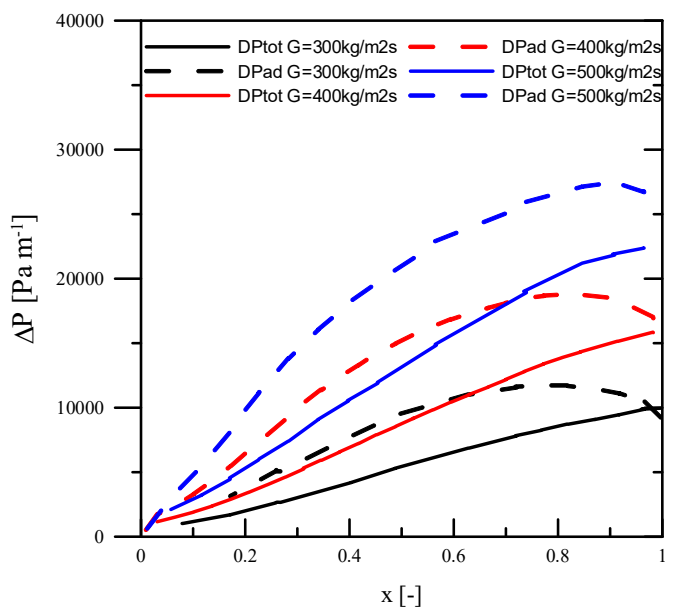

Fig. 2. Experimental values of the total and adiabatic pressure drop of R134a versus exit vapor quality of the $5 \mathrm{~mm}$ tube at Tsat $=19.4^{\circ} \mathrm{C}$.

Figures 3 to 5 shows the experimental adiabatic frictional pressure drops, plotted versus values predicted with selected correlations. Pressure drop models used in this comparison are presented in detail in the introduction section i.e. Zhang and Webb [18] and Thome et al. [13]. The pressure drop increases exponentially with increasing mass flux. It can also be seen that the two-phase pressure drop is increasing for higher exit vapor quality with a maximum around vapor qualities around $x=0.8-0.9$, as reported in the literature.

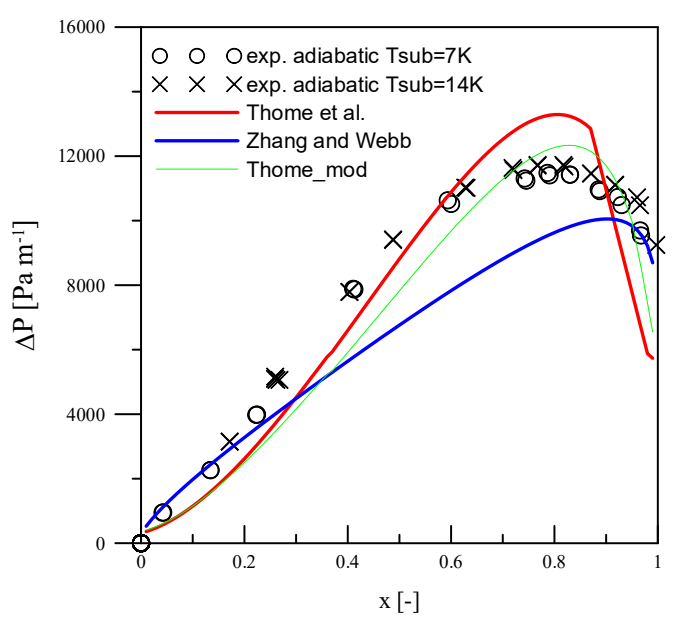

Fig. 3. Exp. values of the adiabatic frictional pressure drop of R134a versus predictions for $G=300 \mathrm{~kg} /\left(\mathrm{m}^{2} \mathrm{~s}\right)$. 


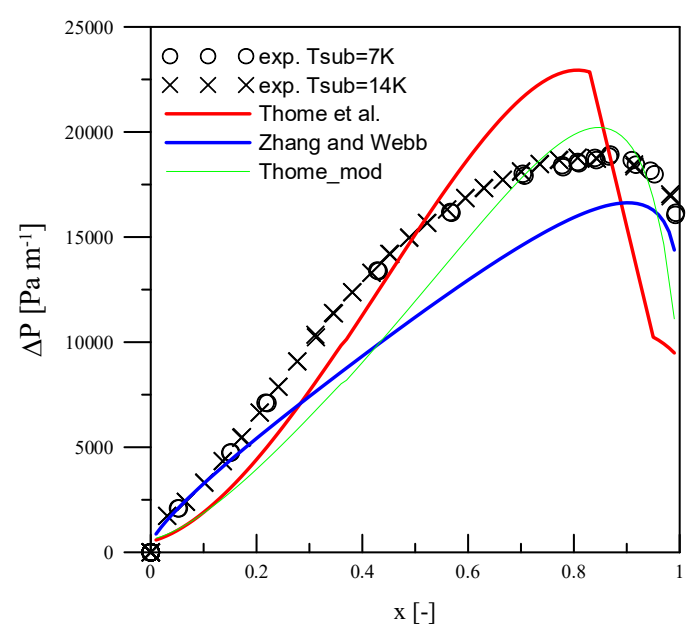

Fig. 4. Exp. values of the adiabatic frictional pressure drop of $\mathrm{R} 134 \mathrm{a}$ versus predictions for $\mathrm{G}=400 \mathrm{~kg} /\left(\mathrm{m}^{2} \mathrm{~s}\right)$.

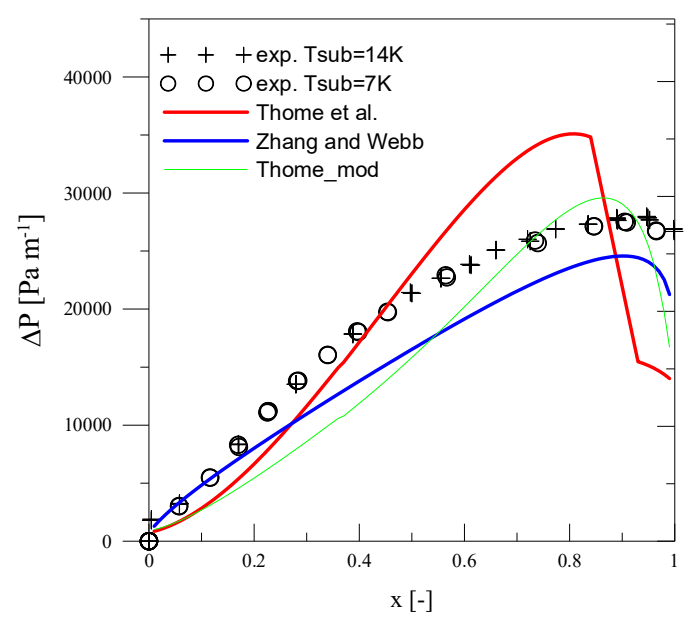

Fig. 5. Exp. values of the adiabatic frictional pressure drop of R134a versus predictions for $G=500 \mathrm{~kg} /\left(\mathrm{m}^{2} \mathrm{~s}\right)$.

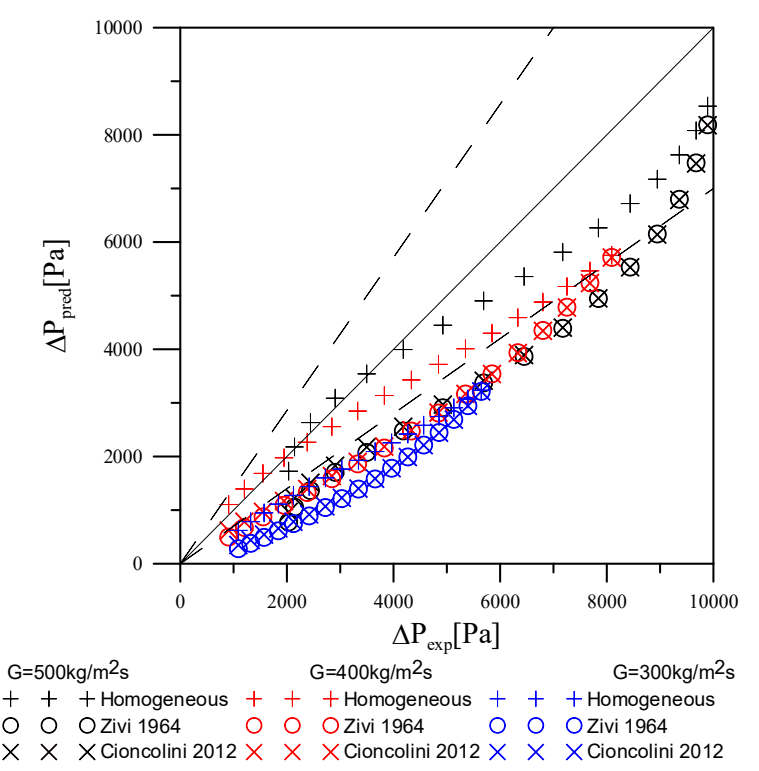

Fig. 6. Exp. values of momentum pressure drop of R134a versus predictions.

The proposed model modification with entrainment effect allows to better predict the peak pressure drop values. As can be clearly seen proposed modification provides better data representation for selected flow range. As the mass flux is lower thus the lowers the entrainment effect thus the modification in case of $G=300 \mathrm{~kg} / \mathrm{m}^{2} \mathrm{~s}$ is closer to original model [13].

The pressure drop component due to acceleration varies with outlet vapor quality and void fraction. Literature models of a void fraction are created with the assumption that the same flow regimes are obtained at the same local liquid and vapor flow rates. In order to calculate the momentum pressure drop from adiabatic and diabatic experiments, a piecewise decomposition of the flow must be performed. Due to the limited data points, polynomial interpolation of the data is necessary as described in [16,29]. Electric heating of the channel allows us to assume constant heat flux density along the heated channel length, therefore a linear change in local thermodynamic vapor quality of the flow can be assumed. Therefore the pressure drop along the heated channel can be recreated by using friction pressure drop values at "local" vapor qualities at heated channel length. Rearranging eq.(3) the momentum pressure drop can be calculated by subtracting frictional pressure drop from measured values of total pressure drop in heated section. This operation for an infinite number of points can be expressed as an integral in form of eq.(11). The accuracy of this method highly depends on polynomial interpolation of the data. For presented data, the best fit error was below $1 \%$, which corresponds to total momentum pressure drop of $1.15 \%$

$$
\Delta P_{a d, d e c o m p a s i t i o n}=\int_{0}^{L} \frac{d}{d z} \Delta P_{a d}(x) d z
$$

From the analysis of data presented in figure 6 , a good consistency with the homogeneous model is visible for all of the cases. Predictions given by homogeneous model compared to other correlations in that flow range differ as much as $50 \%$ corresponding up to $1 \mathrm{kPa}$, for vapor quality range 0.2 to 0.8 . As can be seen, all of the void fraction correlations under predict the experimentally obtained momentum pressure drop. The influence of various void fraction correlations is more pronounced in higher velocities.

\section{Conclusions}

As the first step of this work, an experimental study was undertaken in order to obtain total and frictional pressure drop values during flow boiling of R134a in a smooth horizontal tube, at a saturation temperature of $19.4^{\circ} \mathrm{C}$ with inlet subcooling of 7 and $14 \mathrm{~K}$.

The experimental campaign acquired over 300 experimental data points. Based on gathered experimental data, momentum pressure drop was obtained, from a comparison of the adiabatic frictional pressure drop and total pressure drop in diabatic section.

The flow range was chosen to represent an annular flow pattern.

Verification of the momentum pressure drop predictions showed that all void fraction correlations predict experimental data fits in the range of $\pm 30 \%$. For 
experimental flow range, the homogeneous model yields the best consistency with experimental data.

The proposed modification of the annular flow model allowed to obtain better peak pressure drop prediction.

The authors would like to appreciate funding received from the Research Council of Norway under the FRINATEK Project 231529 .

\section{Nomenclature}

\begin{tabular}{|c|c|}
\hline $\mathrm{c}_{\mathrm{pl}}$ & specific heat, $[\mathrm{kJ} /(\mathrm{kgK})]$ \\
\hline $\mathrm{D}$ & diameter, $[\mathrm{m}]$ \\
\hline $\mathrm{E}$ & liquid entrainment fraction, [-] \\
\hline$f$ & friction factor, [-] \\
\hline $\mathrm{Ft}$ & Froude rate, $[-]$ \\
\hline $\mathrm{G}$ & mass flux, $\left[\mathrm{kg} /\left(\mathrm{m}^{2} \mathrm{~s}\right)\right]$ \\
\hline g & acceleration due to gravity $\left[\mathrm{m} / \mathrm{s}^{2}\right]$ \\
\hline $\mathrm{h}$ & enthalpy $[\mathrm{kJ} / \mathrm{kg}]$ \\
\hline $\mathrm{j}$ & superficial velocity $[\mathrm{m} / \mathrm{s}]$ \\
\hline $\mathrm{L}$ & length [m] \\
\hline $\mathrm{m}$ & mass flow rate $[\mathrm{kg} / \mathrm{s}]$ \\
\hline$\Delta \mathrm{P}$ & pressure drop $[\mathrm{Pa}]$ \\
\hline$\dot{Q}$ & heat flux $[\mathrm{kW}]$ \\
\hline$\dot{q}$ & heat flux density $\left[\mathrm{kW} / \mathrm{m}^{2}\right]$ \\
\hline $\mathrm{Re}$ & Reynolds number[-] \\
\hline $\mathrm{We}$ & Weber number [-] \\
\hline $\mathrm{x}$ & quality [-] \\
\hline \multicolumn{2}{|c|}{ Greek symbols } \\
\hline$\varepsilon$ & void fraction [-] \\
\hline$\mu$ & viscosity [Pas] \\
\hline$\rho$ & density $\left[\mathrm{kg} / \mathrm{m}^{3}\right]$ \\
\hline \multicolumn{2}{|c|}{ Superscripts } \\
\hline ad & adiabatic \\
\hline $\mathrm{c}$ & core \\
\hline fric & frictional \\
\hline $\mathrm{h}$ & heated \\
\hline in & inlet \\
\hline 1 & liquid \\
\hline mom & momentum \\
\hline $\operatorname{mix}$ & mixture \\
\hline out & outlet \\
\hline sat & saturation \\
\hline sub & subcooling \\
\hline static & gravitational \\
\hline tot & total \\
\hline $\mathrm{v}$ & vapor \\
\hline $\mathrm{W}$ & wall \\
\hline
\end{tabular}

\section{References}

1. B. Igliński, G. Piechota, A. Iglińska, M. Cichosz, R. Buczkowski, Clean Technol. Environ. Policy. 18, 45-61 (2016)

2. T. Muszynski, Appl. Therm. Eng. 115, 782-792 (2017)

3. P. Ostrowski, M. Pronobis, L. Remiorz, Appl. Therm. Eng. 84, 390-398 (2015)

4. G. Besagni, R. Mereu, G. Di Leo, F. Inzoli, Int. J.
Refrig. 58, 154-171 (2015)

5. D. Taler, P. Ocłoń, Chem. Eng. Process. Process Intensif. 83, 1-11 (2014)

6. T. Muszynski, S.M. Koziel, Arch. Thermodyn. 37, 45-62 (2016)

7. R. Andrzejczyk, T. Muszynski, Arch. Thermodyn. 38, 3-21 (2017)

8. T. Bohdal, H. Charun, M. Sikora, Int. J. Refrig. 59, 210-223 (2015)

9. T. Muszynski, D. Mikielewicz, Appl. Therm. Eng. 93, 1403-1409 (2016)

10. R. Andrzejczyk, T. Muszyński, Arch. Thermodyn. 37, 137-159 (2016),

11. R. Andrzejczyk, T. Muszynski, Appl. Therm. Eng. 121, 115-125 (2017)

12. T. Muszynski, R. Andrzejczyk, Appl. Therm. Eng. 93, 1360-1366 (2016)

13. J.R. Thome, Engineering data book III (Wolver. Tube Inc. 2010)

14. [14] Y. Xu, X. Fang, Appl. Therm. Eng. 64, 242251 (2014)

15. R. Revellin, P. Haberschill, Int. J. Refrig. 32, 487497 (2009)

16. J.M. Quiben, J.R. Thome, Int. J. Heat Fluid Flow. 28, 1060-1072 (2007)

17. R. Andrzejczyk, T. Muszynski, C. Alberto Dorao, Exp. Therm. Fluid Sci. 83, 78-87 (2017)

18. [18] M. Zhang, R.L. Webb, Exp. Therm. Fluid Sci. 25, 131-139 (2001)

19. J. Garcia, M.P. Porto, R. Revellin, J. Bonjour, L. Machado, Int. J. Refrig. 73, 163-174 (2017)

20. A. Cicchitti, C. Lombardi, M. Silvestri, Energ. Nucl. 7, 417-425 (1960)

21. L. Sun, K. Mishima, Int. J. Multiph. Flow. 35, 47-54 (2009)

22. [22] E.W. Lemmon, M.L. Huber, M.O. McLinden, Phys. Chem. Prop. (NIST 2010)

23. B.N. Taylor, C.E. Kuyatt, NIST Tech. Note. 129720 (1994)

24. Y. Xu, X. Fang, D. Li, G. Li, Y. Yuan, A. Xu, Int. J. Heat Mass Transf. 98, 150-163 (2016)

25. K. Aroonrat, S. Wongwises, Int. J. Heat Mass Transf. 106, 437-448 (2017)

26. R. Revellin, Experimental two-phase fluid flow in microchannel (EPFL, 2005)

27. [27] R. Charnay, R. Revellin, J. Bonjour, Int. J. Refrig. 54, 98-125 (2015)

28. T. Muszyński, R. Andrzejczyk, C.A. Dorao, Arch. Thermodyn. 38, 101-118 (2017)

29. T. Muszynski, R. Andrzejczyk, C.A. Dorao, Int. J. Refrig. 82, 163-173 (2017)

30. C.B. Tibiriçá, D.M. Rocha, I.L.S. Sueth, G. Bochio, G.K.K. Shimizu, M.C. Barbosa, S. dos S. Ferreira, Appl. Therm. Eng. 126, 774-795 (2017)

31. S.E. Haaland, J. Fluids Eng. 105, 89-90 (1983) 